\title{
ESP Course for IT Students at the Middle East College of Information Technology, Sultanate of Oman: Design and Application
}

\author{
Samia Naqvi \\ Middle East College of Information Technology, Sultanate of Oman \\ snaqvi@mecit.edu.om \\ Priya Mathew \\ Middle East College of Information Technology, Sultanate of Oman \\ priya@mecit.edu.om
}

\begin{abstract}
Learners specializing in any discipline require proficiency in both language skills and their specific area of study to cope with tertiary education. This paper reviews strategies used to plan, develop, and implement a content-based language course for learners specializing in Information Technology (IT). Strategies used to develop content-based language courses through the integration of language and research skills with content are explored and applied. Technical description, intensive and extensive reading of authentic IT texts, and a research project form the syllabus to achieve the required outcomes. Collaboration with faculty members of the Department of Computing helped in arriving at the learning outcomes required. This paper also presents the effects of implementing the course on learners' performance in other courses taken concurrently as well as in later stages of academic progression. Curriculum design and application methods discussed here could be applied to ESP courses for other disciplines.
\end{abstract}

\section{Focus of the Paper}

This paper reviews the planning, design, and implementation of an ESP course for learners specializing in IT in the Middle East. It also intends to sum up the perspectives of language teachers who were involved in the process. The efficacy of using a content-based approach in preparing an English language specific course for learners specializing in IT is explored. Content-Based Instruction (CBI) is "an approach to language instruction that integrates the presentation of topics or tasks from subject matter classes within the context of teaching a second or foreign language" (Crandall \& Tucker, 1990, p. 187). According to Krashen and Biber,

One way to provide comprehensible input directly... is by teaching content in English using strategies and techniques that make the content comprehensible to the second language learner. Research confirms that learners in classes where such strategies and techniques are employed acquire impressive amounts of English and learn content matter as well. (1988)

Language Education in Asia, 2010, 1(1), 242-257. http://dx.doi.org/10.5746/LEiA/10/V1/A20/Naqvi_Mathew 
Moving away from teaching language in isolation towards a more integrated context-oriented approach has given rise to an array of language teaching courses that cater to the needs of a specialized audience; the ESP for IT course discussed in this paper is a case in point.

The strategies and application of the ESP for IT course can be adapted to other disciplines, as the paper also discusses the theories and practical considerations fundamental to the design of a curriculum geared towards a specific set of learners.

\section{Background Information}

This case study is based on data gathered from the staff and students of the Middle East College of Information Technology (MECIT), Sultanate of Oman. The college is the country's largest private institution with a student enrollment of approximately 3,000. It has been approved by the Ministry of Higher Education, Oman to offer academic programmes at the undergraduate and postgraduate levels. The academic year comprises two semesters, fall and spring, the duration of each semester being 15 weeks.

Candidates wishing to enroll in the undergraduate programmes in MECIT need to have a minimum 5.5 on the IELTS scale or an equivalent score in the Placement Test conducted by the college. Students who do not qualify for exemption attend a one-year preparatory course for post secondary students called the Foundation Programme (FP); it includes an EAP course which engages learners in note taking, participation in question-answer sessions and mini presentations, guided self study, extensive reading, and completion of a research project on a general topic.

The ESP for IT course aims to bridge the gap between General English and core subjects. The ESP for IT course is a mandatory module to be taken by all first semester students.

Approximately 400 and 200 students register during the fall and spring semesters, respectively. The typical cohort consists of a heterogeneous body of learners from a variety of cultures, family backgrounds, educational milieu, and regions. Two tutorial hours are allotted for each session consisting of 30 to 35 learners. Consultations with faculty members during office hours and self-study are also encouraged.

\section{Key Issues}

The following key issues are considered and analyzed in the paper:

1. What steps need to be taken to prepare an ESP course?

2. Is the ESP for IT course discussed here applicable to other disciplines?

\section{Course Planning and Design}

Discussions with subject specialists and evaluation of learners' work helped the course designers recognize specific learner needs. Inadequate communication skills and limited knowledge of basic scientific and mathematical vocabulary and concepts were identified. Fear of failure when communicating content in a foreign language was observed. It was realized that an ESP course in IT would have to gently introduce learners to their subject area and continue to provide the required language scaffolding.

\section{The Role of the ESP Teacher}

Hutchinson and Waters (2005) argue that ESP teachers do not need specialized subject knowledge in order to teach content-based language courses: 
What kind of knowledge is required of the ESP teacher? ESP teachers do not need to learn specialist subject knowledge. They require three things only:

i. a positive attitude towards the ESP content;

ii. a knowledge of the fundamental principles of the subject area;

iii. an awareness of how much they probably already know.

.... In other words, the ESP teacher should not become a teacher of the subject matter, but rather an interested student of the subject matter.

One final point to note is that, as with learner needs, teacher knowledge is not a static commodity. Many ESP teachers are surprised at how much knowledge of the subject matter they 'pick up' by teaching the materials or talking to students. (p. 163)

Richards (2001) stated that being an effective teacher means more than becoming a skillful and experienced classroom practitioner. It means knowing how to develop and adapt materials, plan and evaluate courses, adapt teaching to learners' needs and function within an institutional setting. Dudley-Evans and St. John (1998) identified additional key roles for the ESP practitioner: collaborator and researcher.

When EFL course instructors become ESP curriculum designers, they find themselves in a unique situation defined by particular learner needs shaped by the nature of the discipline and the often unpredictable levels of language proficiency and content knowledge of the learner. Hence an ESP course designer is not armed with precedent, but rather creates the precedent as no two ESP situations are identical.

\section{The Role of the Subject Specialist}

The curriculum design process of all ESP courses requires a concerted effort from subject specialists and language teachers who assume the role of interested students. Cooperation and collaboration among ESP instructors and subject specialists are key to the success of such courses. At MECIT, lecturers from the Department of Computing and ESP instructors from the Languages Centre worked together to achieve the desired outcomes.

... [subject-specific work] may involve specific collaboration so that there is some integration between specialist studies or activities and the language. This might involve relating the reading component of an EAP course to the actual content of a subject course by exploiting texts in English that present additional relevant material, in other words the subject teacher provides the 'carrier content' for the English course. (Dudley-Evans \& St. John, 1998, p. 15-16)

In this case, discussions between subject specialists and language instructors revealed gaps in learner knowledge and abilities, which were then addressed in the design of the course.

\section{Needs Analysis}

Different types of learners have different language needs and in this instance also, the needs were reasonably specific and were identified to arrive at the course content. The four determinants involved in ESP course preparation suggested by Strevens (1977) were also considered, each according to the learners' objectives:

1) restriction to necessary skills

2) selection of vocabulary, grammar, and language functions

3) themes and topics

4) communicative needs 
Core subject classes were observed in order to know the methods, language, and content learners are engaged in. This highlighted the gap between General English classes and the skills and language required by learners freshly introduced to their specialism. "Needs based language use situations" (Branden, 2007) were identified. The course was designed based on these to let learners realize that what they learn in class is directly applicable to the real world (2007).

A series of discussions between language instructors and tutors from the Computing Department brought to light learners' inadequate knowledge of the language of dimensions and their inability to locate, comprehend, select, and summarise information in the subject area. However, the inadequacy of learners' English language skills as well as knowledge of content was proved by their performance during tutorials as well as in assessments. Basic study skills, such as those taught in the FP, were recognized as an inevitable prelude to subject area complexities.

The need for continuous language support even after completion of the Foundation Programme was unanimously acknowledged by subject specialists as well as learners who were interviewed.

\section{Material Development}

As there was no specific coursebook meeting the requirements of this course, learning material, assessments and the final examination were designed in-house by ESP instructors in consultation with subject specialists. The available coursebooks did not engage the learners' minds as the themes were not relevant, did not suit their skills and abilities, and did not contain all the desired course components. Tomlinson (2008) supports the need for custommade learning material:

The value of engaging the learners' minds and utilising their existing skills seems to be becoming increasingly realised in countries which have decided to produce their own materials through textbook projects rather than rely on global coursebooks which seem to underestimate the abilities of their learners. (p. 9)

In short, ESP instructors and subject specialists built a framework for the course based on the needs analysis and designed suitable material to support the course. The resulting ESP for IT course, its components, and the concepts and methodologies employed are discussed in the next section.

\section{The ESP for IT Course}

The ESP for IT module develops basic technical and report writing skills and presentation skills of a technical and scientific nature. It encourages critical thinking and continuous self assessment, promotes research and cooperative skills, and trains learners to deal with a professional environment.

Nunan (1988) advocates the advantages of informing students about the specific objectives of a course before its commencement. Mager (1975) also views performance objectives as curriculum "signposts" which motivate students to attain the learning outcomes. Thus, on the first day of the course, learners are provided with a Module Information Sheet containing details of objectives, course content, assessments, a list of references for extra reading, passing criteria, attendance requirements, and the institutional policy on academic integrity. 
On successful completion of this course learners are expected to:

- communicate effectively in their academic environment;

- use extensively, both in spoken and written forms, special vocabulary related to their major field of study;

- analyse, evaluate, and interpret information in technical texts;

- develop an effective writing style and tone following academic writing conventions;

- write ethically, logically, and with confidence; and

- provide peers with constructive feedback on their work.

\section{Course Components}

Technical description. This component aims to engage learners in technical writing which involves knowledge of basic geometric shapes, language of dimensions, as well as descriptive writing skills. The outcomes of this component are assessed in an assignment where learners describe an electronic item.

Research project in area of specialization. A research project is one of the major components of the course as it is an ideal medium through which language skills, subject area knowledge, and required research skills are integrated. Beckett (2002) has defined a project as an activity undertaken over a long period of time and includes both individual and group work in developing a research plan, formulating questions, collecting and interpreting data and translating this into a written or oral report. Beckett and Slater's (2005) Project-Framework, a methodology that helps students to learn language, content, and skills simultaneously, is used. It consists of two components: a planning graphic, which provides the categorization of the target language, content, and skills, and a project diary, which provides students with a weekly summarization task.

Language instructors collaborated with subject teachers to draw up a list of research topics. Care was taken to include only those topics that learners are required to be familiar with and students were allowed to choose from the list.

Cooperative learning. Learning opportunities are enhanced if learners work in groups that have structured objectives, clear targets, individual accountability, and equal opportunities. According to Slavin,

...the research done up to the present has shown enough positive effects of cooperative learning, on a variety of outcomes, to force us to reexamine traditional instructional practices. We can no longer ignore the potential power of the peer group... (1983, p.123)

Learners are grouped according to their abilities and then encouraged to choose a research project topic from the list provided. In mixed attainment groups, learners with higher language competency act as resources. The topics are narrowed down in consultation with the instructor who ensures that they do not stray far into a technical forest of strange lexis and complex concepts. Nunan (1992) states, "... tasks in which learners are required to negotiate meaning among themselves in the course of completing an interactive task are particularly suited to language development" (p.4). Thus, in the research project, learners start by collectively formulating a thesis statement and discussing the plan of action.

Group work is monitored through face-to-face discussions between instructor and learners as well as project diaries (see Appendix A). During weekly meetings, group members report on the status of the assigned task for the week and future course of action. This ensures that every 
member of the team is motivated to complete the task on time. The project diary, which records these proceedings, is shared with the instructor during the next tutorial session. Groups are also encouraged to prepare an action plan (see Appendix B) detailing the phases of completion along with time lines and the group member responsible for accomplishing those tasks.

"ESP learners in the same class are unlikely to have the same, or even a similar, level of English. The teacher must expect mixed levels and will need to have strategies and activities to allow for differentiation"(Harding, 2007). By engaging learners in group research projects, maintenance of portfolios and encouraging self-study, the curriculum allows learners of different attainment levels to progress at their individual level of competency through project work.

Project report and presentation. To prepare for the project report, learners are trained in the skills of preparing and administering questionnaires and conducting interviews. Learners are encouraged to choose an organization or an individual to conduct a case study to get firsthand experience and knowledge of their topic. Learners collate and record information from various sources, after which the report is prepared. The report comprises an introduction, three to four chapters depending on the type of topic chosen, and a conclusion.

If a group chooses, for example, e-banking as the research topic, they then choose a specific aspect of e-banking. Learners are then encouraged to visit one of the banks (or two if they are drawing comparisons) and study the system and procedures of e-banking. To avoid plagiarism, a word limit of 300 to 350 words per chapter is specified. To ensure learners use their own words, exhaustive practice in summarizing, paraphrasing, quoting, and referencing is given. Learners present their findings, conclusions, and recommendations on MS PowerPoint.

Extensive reading. Extensive reading is an important part of self-study for the research project; the aim is to improve learners' language abilities, vocabulary, and content area knowledge. To keep track of extensive reading, learners are provided with a reading table (see Appendix C) where they are asked to fill the details of each item read as a part of self-study for the project.

Intensive reading. Authentic ESL texts, selected for intensive reading in consultation with content teachers, aim at enhancing learners' computing-specific vocabulary as well as skimming, scanning, comprehension, and summarizing skills. This component of the course, which is dealt with during tutorials, increases knowledge of vocabulary and reinforces language as well.

Portfolios. "Portfolio assessment techniques offer a powerful means of LSP [Language for Specific Purposes] assessment that can have the additional benefit of empowering learners and second language users" (Pollari, 1997). All learning activities including class notes, evidence of self-study, drafts of the report, and reading logs, are filed in a portfolio. These documents, along with worksheets completed independently and in class, hard copies of information summarized and paraphrased from various sources for the research project and Project Diaries, reflect the learners' degree of motivation and provide tutors with useful insights into learners' progress as well as involvement and capacity for independent learning.

Assessment. Formative assessments are given the same weight as the final examination. The former includes assignments on technical writing, portfolios, report writing and presentations on topics chosen in the subject area. The final examination tests learners' comprehension of technical texts, description of graphical data and theoretical knowledge of research skills. The formative assessments and final examination together achieve the twin objectives of assessing 
language proficiency and knowledge of subject matter. The former comprises the two features of ESP assessments described by Douglas as "authenticity of task and the interaction between language knowledge and specific purpose content knowledge" (2000, p.2).

\section{Feedback and Results}

\section{Teacher Feedback}

Questionnaire. A questionnaire (see Appendix D) was administered to 20 ESL instructors with teaching experience ranging from a year to more than twenty years. The ESP course had been introduced five semesters prior to the administration of this survey. The aim of this survey was to evaluate the efficacy of the planning, design, implementation, and outcomes of a contentbased approach to language learning for learners of Information Technology in the Middle East.

Approximately half the respondents have attended a course in computing. All those who responded in the affirmative said that this experience had helped them guide their learners better. Approximately half the respondents admitted that their knowledge of subject area was limited and this was initially an obstacle in the teaching and learning process. However, with ESP teaching experience, the problem is gradually resolved.

When questioned on the strategies they would adopt in such a situation, consulting a peer was the most popular option, followed by finding answers through research and consulting a subject specialist. One respondent answered that the obstacle would be ignored and the teacher would try to move on. On learners' level of proficiency in subject area, half of the respondents answered that $75 \%$ of learners were unaware of basic mathematical and computing lexis, language of dimensions and calculations, six teachers answered that half were not proficient and four teachers felt that less than a quarter were not proficient in these areas.

Eighteen respondents believed that a research project was ideal for integrating language and content.

Approximately half the respondents felt that the list of research topics was appropriate. Sixtyfive percent of respondents felt that they were able to supervise the direction and depth of content area learners should explore.

Interviews. The ten content teachers interviewed stated that $75-80 \%$ of students are able to cope with the language requirements of the modules that they study in subsequent semesters. Learners are familiar with the language of dimensions and measurements.

The teachers added that learners' speaking skills are ahead of their writing skills. Lack of adequate writing skills impede completion of fluent and error-free written assignments even though the idea is communicated, according to S. Srinivas, an ESP instructor in the Languages Centre (personal communication. June 15, 2010). Ms. Shyamala, a faculty of the Computing Department in MECIT says,

Oral communication has shown an upward trend...there is a slow but gradual improvement. I would say $20 \%$ of students struggle with written assignments, but they have the confidence to have discussions in class and this confidence can only come with improved language skills. 


\section{Post-Course Learner Feedback}

At the conclusion of each semester, all students are required to give feedback on the modules they have completed. This survey is administered online and is accessible to all MECIT students from any computer with Internet access. Questions to engender both quantitative and qualitative responses are included; space is provided for students to fill in their qualitative responses after they have completed the quantitative section. Students are required to complete the questionnaire before they can log into the College Information System (CIS) to access examination results. Table 1 shows five questions selected from the college-wide survey designed to collect feedback from students on each course offered by various academic departments.

\section{Table 1}

\section{Student Feedback Questionnaire Used for Qualitative and Quantitative Responses}

Q1. The language used is easy to understand.

Q2. The exercises, problems, sample questions etc. are helpful and are also from the local environment.

Q3. This module is interesting. I will recommend this to others.

Q4. This module is taught in such a way that it encourages me to study more on my own.

Q5. Learning outcomes of the course have been made clear.

Qualitative responses. Excerpts from qualitative student feedback are given below; the question number is indicated before the response.

Q1. "Personally, I think that this subject is fine, but maybe they should split the students according to their levels of English."

Q2. "How to write an assignment, how to write a research proposal, reading and summarizing, how to prepare a presentation."

Q3. "Should increase the number of hours of lecture because it contains many things which must be examined carefully."

Q3. "Very interesting, a lot of activities and various assignments which enable a student to move forward with good knowledge and expectation. The assignment, reports and presentation played a major role in improving the level of our English Language."

Q4. "Teaches us some things that one must know in academic studies."

Q4. "It's related to the requirement of developing the skills of each individual who will be assigned to write a project or describe any items if he/she joined the work field in the future. It talks in a professional method and foundation of how to do this or that."

Q4. "Group wise it should be removed \& replaced with individual work...as in the end we will discover the full project collapses because of one person."

Q5. "Teaches us how to do research well."

Quantitative analysis of learner responses. The following graphs show the category percentages for 443 student responses to questionnaire items: 


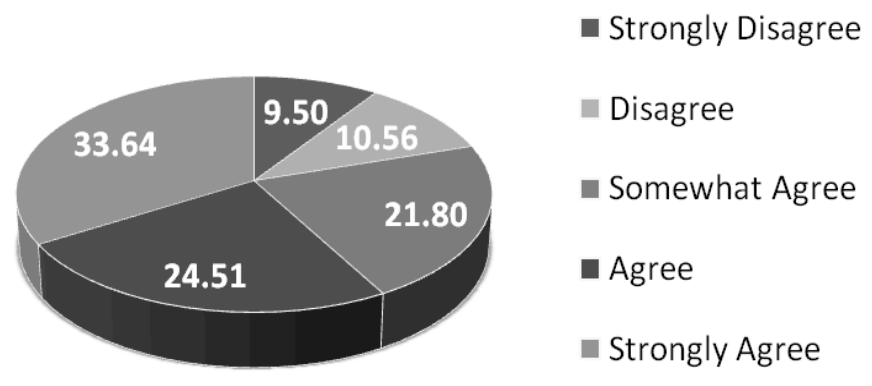

Figure 1. Responses in percentages to questionnaire item 1 "The language used is easy to understand."

Care was taken to ensure that the language used in the handbooks and during tutorials was easy to understand. This was done by introducing specialist vocabulary in stages and not beyond what was needed at this point of academic study.

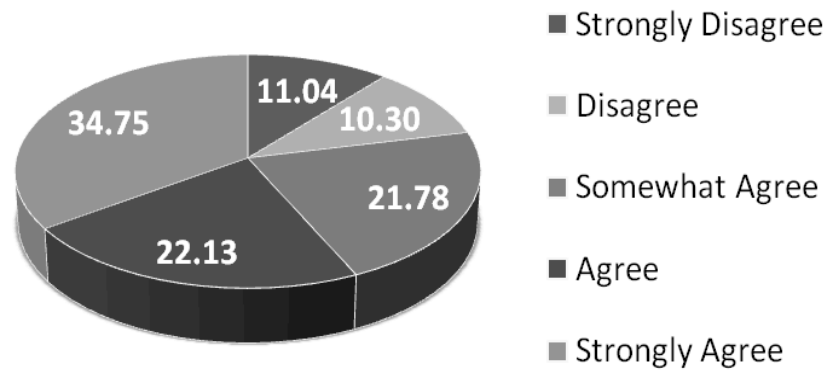

Figure 2. Responses in percentages to questionnaire item 2: "The exercises, problems, sample questions, etc. are helpful and are also from local environment."

Most students find the activities and assessments relevant as they are from the local environment. Reading texts and research project topics are carefully chosen from areas that students would interact with in their professional lives.

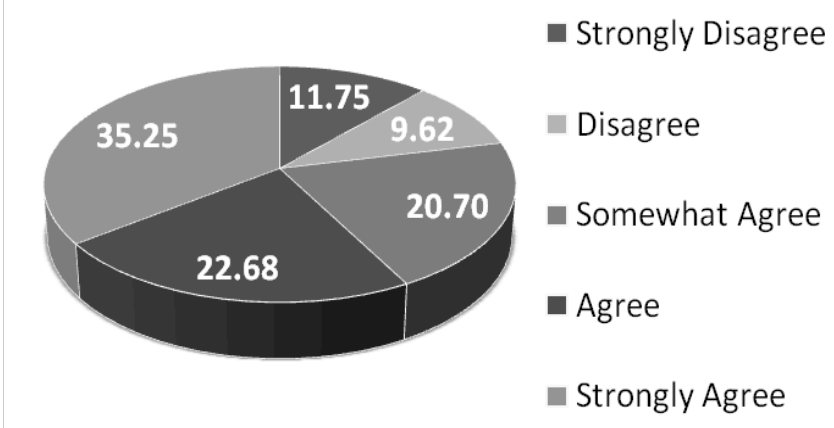

Figure 3. Responses in percentages to questionnaire item 3: "This module is interesting, I will recommend it to others."

Approximately $80 \%$ of students find the module interesting. This indicates that students are motivated, a crucial factor in the learning process. 


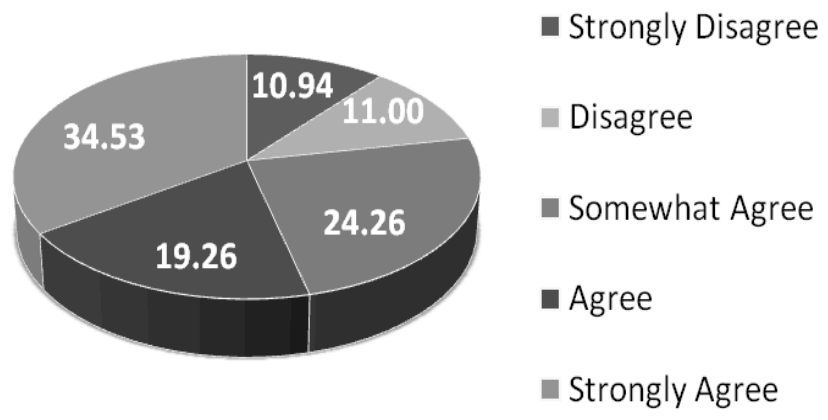

Figure 4. Responses in percentages to questionnaire item 4: "This module is taught in such a way that it encourages me to study more on my own."

More than $75 \%$ of students agree that the ESP for IT course encourages self study. Student participation is significant in assessments such as research projects.

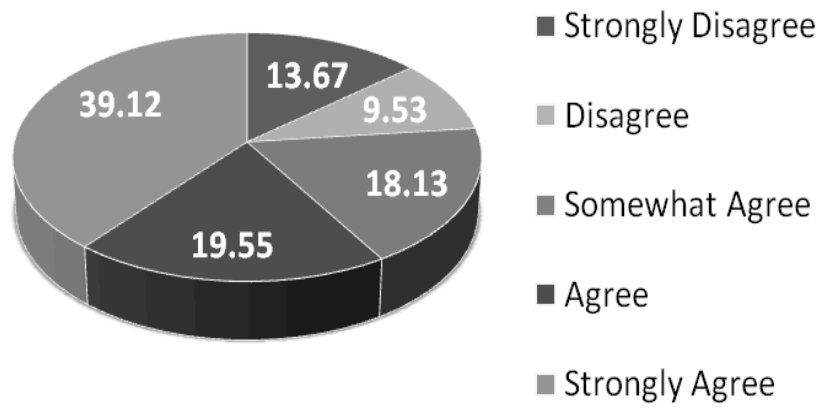

Figure 5. Responses in percentages to questionnaire item 5: "Learning outcomes of the course have been made clear."

The majority of students agreed that they were aware of the learning outcomes of the course. This awareness makes learning purposeful and consequently influences motivation and performance.

\section{ESP Scores}

The results of a language course are not immediately apparent. Hence the examination scores of students over three semesters were compared to find out if performance improved.

ESP results were compared to average marks scored for the other four modules taken concurrently as well as average marks scored in the subsequent semester. The correlation coefficient was found for two batches of students, the results of which are tabulated in Table 2: 


\section{Table 2}

Comparison of ESP Scores with Modules Taken Concurrently and in the Succeeding Semester

\begin{tabular}{|c|c|c|}
\hline Batch 1 & $\begin{array}{l}\text { Correlation } \\
\text { co-efficient }\end{array}$ & $\begin{array}{c}\text { Number of } \\
\text { students }\end{array}$ \\
\hline $\begin{array}{l}\text { ESP scores in Fall } 2008 \text { compared with } \\
\text { average of modules taken concurrently }\end{array}$ & 0.56 & \multirow{2}{*}{304} \\
\hline $\begin{array}{l}\text { ESP scores in Fall } 2008 \text { compared with } \\
\text { average of modules taken in Spring } 2009\end{array}$ & 0.55 & \\
\hline \multicolumn{3}{|l|}{ Batch 2} \\
\hline $\begin{array}{l}\text { ESP scores in Spring } 2009 \text { compared with } \\
\text { average of modules taken concurrently }\end{array}$ & 0.44 & \multirow{2}{*}{167} \\
\hline $\begin{array}{l}\text { ESP scores in Spring } 2009 \text { compared with } \\
\text { average of modules taken in Fall } 2009\end{array}$ & 0.47 & \\
\hline
\end{tabular}

Future studies can examine the correlation of more batches to arrive at a more definite conclusion regarding the positive skew.

\section{Conclusion}

The curriculum design and implementation was a mini project where the focus was to enhance the efficacy of the course by systematic planning, development, and review practices.

Interviews with teachers and the findings of the questionnaire administered to ESP teachers confirmed that experience and close collaboration with subject specialists are the solution to most problems related to delivery of an ESP course. All teachers unanimously agreed that the first time the course was implemented, frequent consultations with subject specialists were necessary. In the process, they acquired subject knowledge which helped them to better guide their learners. The study revealed that collaboration and customized in-house training by experienced ESP instructors provide solutions to difficulties that ESL instructors face in teaching the course because of limited subject knowledge.

Teachers added that group projects provide mixed attainment level learners a chance to work at their pace. This also helps them use stronger peers as a resource. However, the problems encountered when learners are free to search for information on their own still remain, as they invariably choose articles from the Internet or select books that are far above their level of competency. Perhaps this is the price to be paid for "authenticity."

Teachers with limited experience might not be able to implement the curriculum successfully no matter how well it is designed. "In planning a language programme it is therefore important to know the kinds of teachers the programme will depend on and the kinds of teachers needed to ensure that the programme achieves its goals" (Richards, 2001).

Unfortunately there is no ready-made course to train teachers to effectively deliver an ESP course. Perhaps it might not be possible to have such a course with universal applicability going by the "no two ESP situations are identical" theory. However, if the institution is dedicated to quality and professionalism, there could be innovative ways to deal with this. At MECIT, workshops are conducted by experienced ESP teachers for other teachers who are also mentored closely. The course coordinator holds team meetings every two weeks to discuss content delivery, personal experiences, successes, problems, assessments, evaluation, and moderation of assignments. 
Student performance showed a steady improvement in subject courses taken concurrently with the ESP course and in courses taken in the succeeding semester. Student feedback on the course indicates an apparently high degree of learner involvement and satisfaction.

\section{Recommendations}

The challenge faced by ESP teachers is to discover ways in which knowledge of language teaching skills can be adapted for the teaching of ESP. The techniques and strategies outlined below are general in scope and therefore can be used by other course designers for the planning and implementation of their ESP programmes.

ESP teachers should seek help from content specialists in planning appropriate lessons. Both the language instructor and the subject specialist need to work closely in order to attempt to bridge the gap between language and content.

Subject specialists can design a short course for prospective ESP teachers that would familiarise them with essential lexis and concepts before the commencement of each semester. The ESP teacher would also benefit from observing learners during content teaching tutorials.

Language instructors, in turn, can provide valuable experience to content teachers regarding teaching methodology. Tutorials conducted by subject specialists usually follow the lecture method. Class observations and interviews conducted in MECIT revealed that communicative strategies are not employed in content classes. This method of language teaching could be adapted to the teaching of particular disciplines. Observing language teachers at work could also help content specialists to implement these strategies.

These efforts to learn from each other would ideally help in reviewing and making continuous improvements in curriculum and delivery. Shared responsibility brings about deeper perceptions of the complexities involved in language learning. Most of all, learners feel at ease when this attitude is reflected in the classroom. They perhaps can be coaxed into thinking that the English language is, after all, not trying to defy all their attempts to understand it.

\section{Biodata}

Samia Naqvi, B.A, B.Ed, M.A., TEFLA, works at the Middle East College of Information Technology, Muscat. She participates in the teaching, design, development, delivery, and evaluation of ESP courses. Her papers include "The Impact of Arabic Writing Orientation on the Acquisition of English." She wrote "English Grammar" for Arab students.

Priya Mathew, M.A., CELTA, works at the Middle East College of Information Technology, Sultanate of Oman. She has experience in developing curricula and teaching ESP and EAP for IT courses. Research interests include integration of study and language skills, factors influencing motivation and study in Arab learners, and academic advising.

\section{References}

Beckett, G. H. (2002). Teacher and student evaluations of project-based instruction. TESL Canada Journal, 19(2), 52-56.

Beckett, G. H., \& Slater, T. (2005). The project framework: A tool for language and content integration. English Language Teaching Journal, 59(2), 108-116. http://dx.doi.org/10.1093/eltj/cci024

Branden, K. V. (2007). Practice in perfect learning conditions? In R. M. DeKeyser (Ed.), Practice in a second language - Perspectives from applied linguistics and cognitive psychology (pp.161-175). Cambridge, England: Cambridge University Press. 
Crandall, J., \& Tucker, G. R. (1990). Content-based instruction in second and foreign languages. In A. Padilla, H. H. Fairchild, \& C. Valadez (Eds.), Foreign language education: Issues and strategies. Newbury Park, CA: Sage.

Douglas, D. (2000). Assessing languages for specific purposes. ( $2^{\text {nd }}$ ed.). Cambridge, England: Cambridge University Press.

Dudley-Evans, T., \& St. John, M. J. (1998). Developments in English for specific purposes. A multi-disciplinary approach. Cambridge, England: Cambridge University Press.

Harding, K. (2007). English for specific purposes. Oxford, England: Oxford University Press.

Hutchinson, T., \& Waters, A. (2005). English for specific purposes: A learning-centred approach. Cambridge: Cambridge University Press.

Krashen, S., \& Biber, D. (1988). On course: Bilingual education's success in California. Sacramento, CA: California Association for Bilingual Education.

Mager, R. (1975). Preparing instructional objectives. Palo Alto, CA: Fearon.

Met, M. (1991). Learning language through content: Learning content through language. Foreign Language Annals, 24(4), 281-295. http://dx.doi.org/10.1111/j.19449720.1991.tb00472.x

Nunan, D. (1988). Syllabus design. Oxford, England: Oxford University Press.

Nunan, D. (Ed.). (1992). Collaborative language learning and teaching. Cambridge, England: Cambridge University Press.

Pollari, P. (1997). Could portfolio assessment empower ESL learners? Portfolios in the teaching of English as a foreign language in Finnish upper secondary school. In A. Huhta, V. Kohonen, L. Kurki-Suonio, \& S. Luoma (Eds.), Current developments and alternatives in language assessment: Proceedings of LTRC96. Jyvaskyla, Finland: University of Jyvas.

Richards, J. C. (2001). Curriculum development in language teaching. New York, NY: Cambridge University Press.

Slavin, R. E. (1983). Cooperative learning. New York, NY: Longman.

Strevens, P. (1977). Special purpose language learning: A perspective [Survey article]. Language Teaching and Linguistics: Abstracts, 10(3), 145-163. http://dx.doi.org/10.1017/S0261444800003402

Tomlinson, B. (2008). Materials development in language teaching. Cambridge, England: Cambridge University Press. 


\section{Appendix A \\ ESP Project Diary}

Topic:

Teacher's signature:

Date: Time of meeting: From:

To:

1. Name:

Task:

Stage of completion:

2. Name:

Task:

Stage of completion:

3. Name:

Task:

Stage of completion:

4. Name:

Task:

Stage of completion:

Future plans:

Agenda for the next meeting:

Appendix B

Action Plan

\begin{tabular}{|l|l|l|l|}
\hline SI. No & Task & Responsible Person & Timelines \\
\hline & & & \\
\hline & & & \\
\hline & & & \\
\hline & & & \\
\hline & & & \\
\hline & & & \\
\hline & & & \\
\hline
\end{tabular}




\section{Appendix C}

\section{Reading Record}

Keep a record of the material you read for your project during the semester. This sheet is an important part of your portfolio.

\begin{tabular}{|c|c|c|c|c|}
\hline SI. No & Date & No. of Pages & Resource & Time \\
\hline 0 & March 6 & 7 pages & Book: Webster Dictionary, 2002 & 30 minutes \\
\hline 1 & & & & \\
\hline 2 & & & & \\
\hline 3 & & & & \\
\hline 4 & & & & \\
\hline 5 & & & & \\
\hline 6 & & & & \\
\hline 7 & & & & \\
\hline 8 & & & & \\
\hline 9 & & & & \\
\hline 10 & & & & \\
\hline
\end{tabular}

Points to remember:

1. Read at least 100 pages on your topic from various resources

2. Take notes and make reference as you read

3. Submit a Project Proposal 10 weeks before the last date of the project.

4. A report of the project should be made.

5. It should be typed: Font Type: Times New Roman Font Size: 12

6. A PowerPoint Presentation to be made a week before the beginning of End-Semester exams.

\section{Appendix D}

\section{Teacher Questionnaire}

\section{Content-based Instruction in ESP for IT}

Learners specializing in any discipline require a certain degree of proficiency in English language skills as well as their specific area of study to cope with tertiary education. This questionnaire evaluates the efficacy of the planning, design, implementation and outcomes of a content-based approach to language learning for learners of Information Technology in the Middle East.

ESL teaching experience in years

$$
\begin{aligned}
& 0-5 \\
& 6-10 \\
& 11-15 \\
& 16-19 \\
& 20 \text { and above }
\end{aligned}
$$


1. Have you attended a course in computing?

yes

no

If yes, please answer Questions 2 and 3.

2. Please specify the course details.

3. Do you think this has helped you guide your learners better?

yes

no

4. Does your inadequate knowledge of content hinder the teaching and learning process?

yes

no

5. If you feel that your subject knowledge is inadequate to handle the course, you

consult a content teacher

consult a peer (language teacher who is more experienced)

find answers through research

ignore and move forward

6. Approximately what percentage of your learners is not aware of basic mathematical and computing lexis, language of dimensions and calculations?

$$
\begin{aligned}
& 25 \% \\
& 50 \% \\
& 75 \% \\
& 100 \%
\end{aligned}
$$

7. A research project as the major component of the course helps in the integration of language skills and content.

yes

8. The research topics for projects provided by the computing department were appropriate to the level of your learners.

$$
\text { yes }
$$

no

9. While teaching the module 'ESP for $\mathrm{IT}^{\prime}$ ', were you able to supervise the direction and depth of content area learners should explore about their thesis?

yes

no

If yes, please elaborate the difficulties in guiding your learners.

Thank you for your valuable responses. 